\title{
PENGARUH LATIHAN KARET BAN TERHADAP KECEPATAN PUKULAN KUMITE GYAKU TZUKI UNTUK ATLET INKANAS KOTA BENGKULU
}

\section{Lingga Dwi Pranata}

PENJAS FKIP UNIB, e-mail: pranatadwipranata54@gmail.com

\author{
Yarmani \\ Universitas Bengkulu \\ Tono Sugihartono \\ Universitas Bengkulu
}

\begin{abstract}
Abstrak
Penelitian ini bertujuan untuk mengetahui apakah ada pengaruh yang signifikan yan latihan pukulan dengan menggunakan karet ban terhadap peningkatan kecepatan pukulan Kumite Gyaku Tsuki untuk atlet Inkanas Kota Bengkulu. Metode penelitian yang digunakan adalah metode eksperimen dengan variabel bebas adalah latihan dengan menggunakan karet ban dan variabel terikat adalah peningkatan kecepatan pukulan Kumite Gyaku Tsuki. Sampel yang digunakan pada penelitian ini adalah atlet Inkanas Kota Bengkulu yaitu sebanyak 30 atlet. Instrumen penelitian pukulan Kumite Gyaku Tzuki validitas dengan sebesar 0,71 dan reliabilitas 0,64 . Hasil analisis statistik data menunjukan latihan pukulan dengan menggunakan karet ban memberikan pengaruh yang lebih baik dan signifikan terhadap peningkatan kecepatan pukulan Kumite Gyaku Tsuki hal ini karena t-hitung 21,64 dan $t_{\text {tabel }}$ dengan taraf signifikan $\propto 5 \%$ di peroleh niai sebesar 2,00. Kesimpulan penelitian adalah latihan pukulan dengan menggunakan karet ban memberikan pengaruh yang lebih signifikan dari pada latihan pukulan dengan tidak menggunakan karet ban terhadap peningkatan kecepatan pukulan Kumite Gyaku Tsuki untuk atlet Inkanas kota Bengkulu.
\end{abstract}

Kata Kunci : Latihan Beban Gaya-pegas Karet Ban.

\begin{abstract}
This research arms to determine whether there is a significant effect trough exercise which was using rubber tire blow to increase the speed blowing of Gyaku Tsuki Kumite for the athletes Inkanas of Bengkulu City. The method of this research is an experimental method with an exercise which was using rubeber tires as an independent variable and the increasing blow speed of Gyaku Tsuki kumite as the dependent variabel. The sample of this study were 30 athletes in Inkanas Bengkulu city. The instruments of Kumite blow Gyaku Tzuki validity was 0.71 and to 0.64. the Statistical analysis of data showed the exercise blowing which was using rubber tires give better effect and significantly increased to the speed blowing of Gyaku Tsuki Kumite, showed by the t-test 21.64 and t-tabel showed the significance level of 5\%. It was obtained $\alpha$ value of 2.00. The conclusion of this study was the practice of using rubber tires blowing gave a significant effect rater than not using
\end{abstract}


rubber tires blowing toward the increased of speed Gyaku Tsuki Kumite blow to the athlete of Inkanas Bengkulu city.

Keywords : Load Exercises Tire Style.

\section{PENDAHULUAN}

Berdasarkan pengamatan peneliti selama ini atlet-atlet Inkanas Bengkulu mempunyai kelemahan pada kecepatan pukulan Kumite Gyaku Tzuki yang dimana kecepatan pukulan kumite tersebut sangat mempengaruhi penyerangan atau pertahanan atlet tersebut. Hal itu terjadi karena kurangnya disiplin atlet dalam mengikuti latihan dan juga kecepatan pukulan sangat mempengaruh penyerangan atau pertahanan atlet untuk memperoleh poin. Komponen yang berpengaruh seperti yang diuraikan diatas harus dilatih sesuai dengan porsi yang di harapakan pada cabang olahraga karate tersebut.

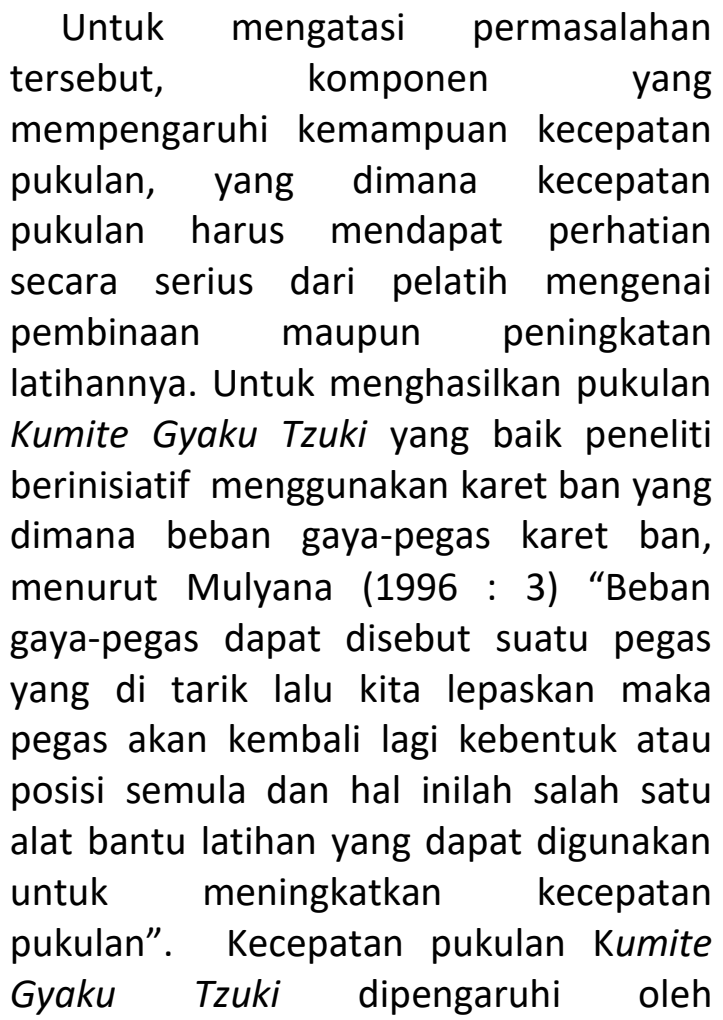

kemampuan otot lengan atas/lengan bawah otot-otot tersebut adalah :

Syaifuddin (1997:41-46), Lengan Atas : M. deltoloit, M. subskapularis, $M$. supraspinatus, $M$. infraspinatus, $M$. teres mayor, $M$. teres minor. Lengan bawah : Otot kedang, Otot ketul, Otot-otot tangan. Jika kekuatan otot-otot lengan lemah maka dapat diprediksi bahawa pukulan dalam teknik Pukulan Kumite Gyaku Tzuki juga akan lemah.

Rumusan masalah dalam penelitian ini yaitu: 1. kurang kecepatan pukulan Kumite Gyaku Tzuki untuk menyerang lawan dan bertahan. 2. Mempunyai kelemahan pada kecepatan pukulan Kumite Gyaku Tzuki. Tujuan yang ingin di capai penelitian ini adalah: untuk mengetahui Pengaruh Latihan Beban Gaya-Pegas Karet Ban Terahadap pukulan Kumite Gyaku Tzuki untuk atlet Karate Inkanas Kota Bengkulu.

Peningkatan Latihan menurut Bompa (1999 : 46) terjadinya peningkatan dalam latihan terjadinya dalam waktu 2-6 minggu tetapi biasanya 4 minggu (1 bulan).hal yang diperhatikan adalah terjadi peningkatan dalam latihan apabila latihan dilakukan minimal $3 x$ seminggu, dan maksimal $12-14 x$ dalam seminggu (sehari 2 sesi), sebab dalam keadaan normal,kelelahan yang timbul akan dapat diatasi dalam waktu antara 12-24 jam dan setelah itu atlet akan merasa segar dan bugar kembali JHarsono, 1988: 135). 
Prinsip-prinsip Latihan

Menurut Lubis, (2013 : 12-22) prinsip-prinsip latihan adalah hal yang wajib diketahui oleh seorang pelatih agar tujuan latihan dapat tercapai sesuai tujuannya. Ada beberapa prinsip latihan sebagai berikut :

Multilateral

Spesialisasi, Individual.

Beban Berlebihan (Over Load), Memperhitungkan Perbedaan Gender, Variasi Latihan, Pengembangan Model Latihan.

Metode Latihan

Dalam Anggoro (2014), "latihan merupakan suatu proses yang sistematis dalam menyiapkan atlet pada suatu kegiatan. Proses dilakukan secara berulang-ulang dengan beban yang semakin meningkat". Latihan pada prinsipnya adalah memberikan tekanan atau stress secara teratur, sistematis, berkesinambungan, sedemikian rupa sehingga dapat meningkatkan kemampuan fisik di dalam kemampuan kerja.

Teknik Karate

Menurut Nastiti, (2008 : 9), teknik Karate menjadi tiga bagian utamanya yaitu Kihon (Tehnik Dasar), Kata (Jurus), Kumite (Pertarungan).

Beban

beban adalah salah satu bentuk latihan tahanan untuk meningkatkan kekuatan. Prawirasaputra, (2000). Sedangkan menurut Harsono, (1988) Latihan tahanan tersebut harus dilakukan sedemikian rupa sehingga atlet harus mengeluarkan tenaga maksimal atau hampir maksimal untuk menahan beban. Beban tersebut sedikit demi sedikit bertambah berat agar perkembangan otot terjamin.

\section{Gaya-Pegas Karet Ban}

Gaya-pegas dapat disebut suatu pegas yang di tarik lalu kita lepaskan maka pegas akan kembali lagi kebentuk atau posisi semula dan hal inilah yang dimaksud dengan gaya pegas. Pegas juga memiliki sifat unik, yaitu sifat elastis atau elastisitas, sedangkan elastisitas itu sendiri adalah kemampuan suatu benda (karet) untuk kembali ke bentuk awalnya segera setelah gaya luar yang diberikan kepada benda tersebut dihilangkan (dibebaskan

\section{Kecepatan}

Kecepatan merupakan salah satu aspek kemampuan yang di perlukan dalam cabang olahraga tertentu. Kecepatan adalah kemampuan untuk melakukan gerakan yang sejenis secara berturut-turut dalam waktu dalam sesingkat-singkatnya, atau kemampuan untuk menempuh suatu jarak dalam waktu yang sesingkat-singkatnya.

Pengaruh Antara Beban Gaya-Pegas Karet Ban Terhadap Kecepatan Pukulan Kumite Gyaku Tzuki

Mengkaji pengaruh latihan beban gaya-pegas karet ban antara kecepatan tendangan. Kecepata tendangan dapat di tingkatkan menggunakan latihan beban yaitu dengan latihan gaya pegas karet ban. tahanan karet merupakan alat bantu latihan yang dapat digunakan untuk meningkatkan kecepatan tendangan karena latihan ketahan dapat mengembangkan kecepatan. Martens, (2004 : 325). 


\section{METODE}

Teknik Pengumpulan Data

Pretest

Pretest dilakukan untuk mengetahui kecepatan pukulan Kumie Gyaku Tzuki sebelum diberikan latihan beban gayapegas karet ban. Bertempat di aula balai koprasi sawah lebar pada pukul 16.00. Dalam tes ini diperlukan petugas pengukur waktu 2(dua) orang, pemberi aba-aba dan pencatat hasil.

Posttest

Posttest dilakukan untuk mengetahui pengaruh latihan beban gaya-pegas karet ban terhadap kecepatan pukulan Kumite Gyaku Tzuki untuk atlet Karate Inkanas Kota Bengkulu. Bertempat di aula balai koprasi sawah lebar. Balai koprasi sawah lebar pada pukul 16.00. Dalam tes ini diperlukan pengukur waktu 2(dua) orang, pemberi aba-aba dan pencatat hasil

\section{HASIL PENLITIAN DAN PEMBAHASAN}

Hasil

Dari skor hasil tes awal dilakukan perhitungan mean $(\bar{x})$ 40,8,standar deviasi (s) 4,69dan varian $\left(s^{2}\right) \quad 21,99$ masing-masing atlet data tersebut.

Begitu juga tes akhir yang telah di uji, maka dilakukan perhitungan mean $(\bar{x})$ 63,53, standar deviasi (s) 3,99dan varian $\left(s^{2}\right) \quad 15,92$ masing-masing atlet data tersebut.

Penguji Persyaratan Analisis

Sebelum mengadakan perhitungan uji $\mathrm{t}$ terlebih dahulu dilakukan uji normalitas. Dari uji normalitas yang dilakukan sampel didapat harga. $t_{\text {hitung }}$ dan $t_{\text {tabel }}$ tes awal 6,26 dan tes akhir 3,73 pada taraf signifikan 0,5 di peroleh nilai 11,07. Maka simpulkan bahwa data normal di lihat dari . $t_{\text {hitung }}$ lebih kecil dari $t_{\text {tabel }}$.

Dari perthitungan antara $x_{\text {thitung }}^{2}$ dan $x_{\text {tabel }}^{2}$ tes awal dan tes akhir maka dapat 3,19 dan di lakukan pada taraf signifikan 0,5 di peroleh nilai 3,84. Maka dapat di simpulkan bahwa nilai homogen.

Uji Hipotesisi Penelitian

Setelah dianalisis data dilakukan nilai t antara tes awal dan tes akhir pukulan kumite gyaku tzuki sebesar 21,64 dan selanjutnya nilai $t$ yang diperoleh dibandingkan dengan $t_{\text {tabel }}$ pada taraf signifikan 0,05 dengan derajat kebesaran 58 ternyata nilai $\mathrm{t}$ yang diperoleh lebih besar dari nilai $t_{\text {tabel }}$ yaitu 21,64 $>2,00$. Hal ini berarti terdapat peningkatan pengaruh latihan karet ban terhadap pukulan Kumite Gyaku Tzuki.

\section{Pembahasan}

Berdasarkan hasil penelitian dan analisis statistik yang telah kemukakan di atas, selanjutnya pada bagian ini akan dikaitkan pembahasan tentang pengaruh latihan beban gaya-pegas karet ban terhadap kecepatan pukulan Kumite Gyaku Tzuki untuk atlet karate Inkanas Kota Bengkulu.

Mulyana (1996 : 3) bahwa Latihan menggunakan Tahanan karet dapat diartikan juga sebagai gerakan suatu model latihan dengan meluruskan tungkai atau memperbesar sudut antara tulang-tulang pada suatu persendian. Maka latihan beban gaya pegas karet ban terhadap kecepatan pukulan Kumite Gyaku zuki, otot-otot lengan atas/lengan bawah sangat mempegaruhi untuk melakukan pukulan Kumite Gyaku Tzuki 
di karenakan power dari otot-otot sangat mempengaruh untuk kecepatan pukulan tersebut. Selain itu juga otot tungkai mempengaruh pukulan Kumite Gyaku Tzuki karena otot tungkai membantu agar pukulan Kumite Gyaku Tzuki di lakukan dengan sempurna atau yang di harapkan. Kecepatan juga merupakan salah satu aspek kemampuan yang di perlukan dalam cabang olahraga tertentu, kecepatan adalah kemampuan untuk melakukan gerakan yang sejenis secara berturut-turut dalam waktu yang sesingkat-singkatnya, atau kemampuan untuk menempuh suatu jarak dalam waktu yang sesingkat-singkatnya. Maka terdapat hubungan yang signifikan latihan beban gaya pegas terhadap peningkatan kecepatan pukulan Kumite Gyaku Tzuki. Hasil penelitian ini bisa dilihat persamaanny di kajian penelitian relevan BAB II halaman 19.

Dari analisis uji t di dapat nilai $t_{\text {hitung }}$ pukulan Kumite gyaku tzuki lebih besar dari nilai $t_{\text {tabel }}\left(t_{\text {hitung }} 21,64\right.$ dan $t_{\text {tabel }}$ 2.00 ), pada taraf yang signifikan 0,05. Hal ini menunjukan bahwa latihan mengunakan karet ban mempunyai pengaruh latihan yang signifikan untuk meningkatkan kemampuan pukulan Kumite Gyaku Tzuki pada cabang olahraga beladiri karate . hal ini dapat dilihat pada peningkatan mean.

Dengan demikian latihan beban gaya pegas karet ban sangat signifikan untuk meningkatkan kecepatan pukulan Kumite Gyaku Tzuki untuk atlet karate Inkanas Kota Bengkulu dan juga bisa menunjang prestasi meraka untuk mengikuti openopen turnamen di daerah dan nasional maupun internasion.

\section{PENUTUP}

\section{Simpulan}

Berdasarkan uraian analisis data dan pembahasan yang diatas, maka selanjutnya peneliti dapat mengemukakan kesimpulan, yang dimana hasil $t_{\text {hitung }}>t_{\text {tabel }}$, dari uji $t_{\text {hitung }}$ di peroleh sebesar 21,64 dan $t_{\text {tabel }}$, diperoleh angka dengan taraf signifikan $\propto 5 \%$ di peroleh nilai sebesar 2,00 . Di dapatkan nilai rata-rata mean( $\bar{x}$ ) dari data statistik tes awal diperoleh sebesar 40,8 dan tes akhir di peroleh sebesar 63,53. Artinya Bahwa latihan beban gaya-pegas karet ban dapat berpengaruh secara signifikan dalam meningkatkan kecepatan pukulan Kumite Gyaku Tzuki.

\section{Saran}

Berdasarkan kesimpulan hasil penelitian di atas maka disarankan :

Bagi atlet Karate bisa memahami tentang prioritasnya dalam mengikuti latihan agar kondisi fisiknya dan kemampuannya terus bisa meningkat.

Bagi para pelatih atau pembina olahraga beladiri karate tingkat pemula dan sebaliknya agar menggunakan metode latihan jangan menoton cobalah menggunakan metode variasi atau modifikasi yang dimana dengan cara latihan tersebut bisa meningkatkan prestasi atlet dan juga agar setiap latihan atlet tidak merasa bosan.

bagi peneliti untuk membantu para pelatih dan pembimbing melakukan latihan kondisi atletnya sebelum mengikuti pertandingan, kalau kondisi atletnya segar bugar,fisik,mental dan tekniknya bagus pasti atlet mengikuti pertandingan dengan semaksimalnya. 


\section{DAFTAR PUSTAKA}

Anggoro, setra w. (2014). Kontribusi Kekuatan Otot Lengan dan Kelincahan Terhadap Keterampilan Mae Geri atlet Karate Lemkari Kota Bengkulu. Universitas Bengkulu.

Arikunto, Suharsimi. (2010). Prosedur Penelitian Suatu Pendekatan Praktik. Jakarta: PT. Rineka Cipta.

Fajriani, Nurasifa. Wina, (2011). Mengenal Senam Alat : Jakarta Timur : PT Wadah Ilmu.

Lubis, Johansyah, (2013). Panduan Praktis Penyusunan Program Latihan : Jakarta : Rajawali Pers

Nastiti, Dewi, (2008), Menjadi Karateka. Jakarta : Be Champion.

Rudianto, Dody, (2010), Seni Beladiri Karate. Jakarta : Golden Terayon Pres.

Sugiyono, (2014), Metode Penelitian Kuantitatif. Bandung : Alfabeta.

Syaifuddin, 1997, Anatomi dan Fisiologi untuk Siswa Perawat : Jakarta : Suku Kedokteran EGC.

Widiatusti, (2011), Tes dan Pengukuran Olahraga : Jakarta

Tangkudung, James. (2012). Kepelatihan Olahraga Pembinaan Prestasi Olahraga. Jakarta: Cerdas jaya ,(2016).Macam-macam Metodologi Penelitian. Jakarta: Lensa Media Pustaka Indonesia ,(2018). Sport Psychometrics Dasar-dasar dan instrument Psikometri. Depok :Rajagrafindo persada
Undang - Undang RI No.3 Tahun 2005, Tentang Sistem Keolahragaan Nasional. 